
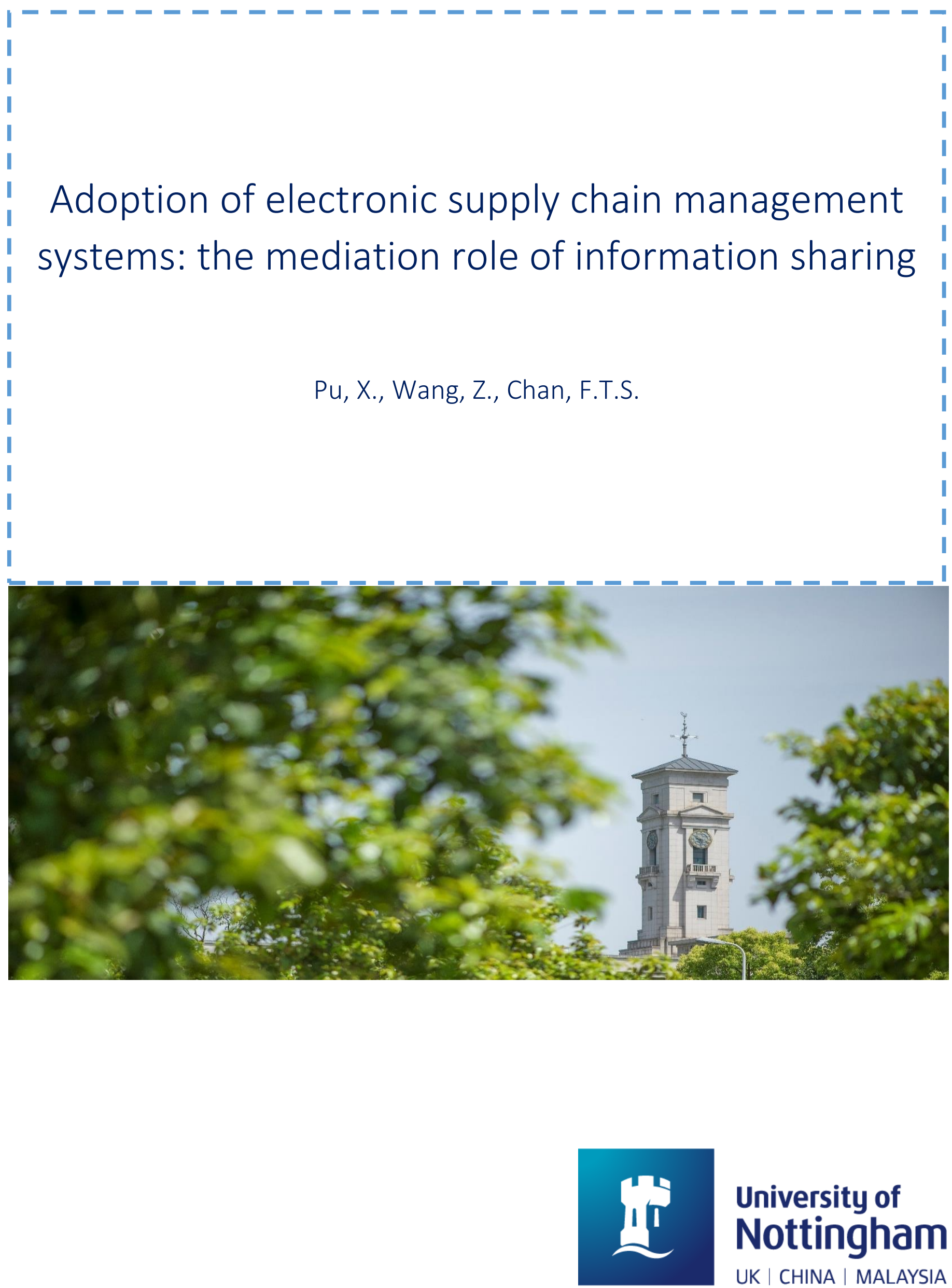
University of Nottingham Ningbo China, 199 Taikang East Road, Ningbo, 315100, Zhejiang, China.

First published 2020

This work is made available under the terms of the Creative Commons Attribution 4.0 International License:

http://creativecommons.org/licenses/by/4.0

The work is licenced to the University of Nottingham Ningbo China under the Global University Publication Licence:

https://www.nottingham.edu.cn/en/library/documents/researchsupport/global-university-publications-licence-2.0.pdf 


\title{
Adoption of Electronic Supply Chain Management Systems: the Mediation Role of Information Sharing
}

\begin{abstract}
Purpose: Based on structural embeddedness theory and resource dependence theory, this research aims to examine the mediation role of information sharing in the relationship between dependency structures and eSCM adoption a firm's intention to adopt electronic supply chain management systems (eSCM).

Design/methodology/approach: A survey questionnaire was undertaken from 212 companies based in Mainland China. Three stage least squares (3SLS) regression was employed to test the research model.

Findings: The results from 3SLS regressions showed that the effect of interdependence on eSCM adoption intention is fully mediated through information sharing when relationship duration is either below or about the mean. Interdependence and dependence disadvantage was shown to have significant positive effects on eSCM adoption while the effect of dependence advantage was statistically insignificant. Relationship duration was found to negatively moderate the relationship between information sharing and adoption intention.

Originality/value: Through investigating factors of inter-organizational relationships, this study fills the knowledge gap in the traditional paradigms which ignore the collaborative nature of eSCM and analyse related problems based on a single firm's point of view.
\end{abstract}

Keywords: supply chain management systems, embeddedness theory, resource dependence theory, dependence structure, inter-organizational relationships 


\section{Introduction}

With the onset of globalization, supply chains have evolved into complex, hyperconnected networks involving vast number of interdependent tasks, operations and stakeholders. Electronic supply chain management systems (eSCM) have been suggested to be the key to cope with the challenges and risks arising from the longer and more complex supply chains. Based on web-technologies and open logistic standards, eSCM provides the digital enablers of operational activities both within and across organizational boundaries (Wu and Chuang, 2010; Liu et al., 2015). Compared with traditional proprietary enterprise systems such as electronic data interchange (EDI) systems, eSCM resolves the trade-offs between integration and flexibility, which can support broader network access and channel deployment at low cost (Sodero et al., 2013; Pu et al., 2018c). With eSCM, companies can seamlessly integrate and streamline disparate supply chain processes, and exchange real-time, rich-content information on various supply chain activities such as inventory, procurement, delivery and product design (Chan et al., 2012; Liu et al., 2015). Therefore, eSCM has the ability to facilitate supply chain communication, coordination, and collaboration at technical, operational and strategic levels (Ke et al., 2009; Liu et al., 2010), which is critical for building operational competitiveness and achieving business success.

Despite the tremendous upside potential of eSCM, most companies have been hesitant or reluctant to adopt electronic tools to digitalize supply chain practices - a phenomenon that has drawn much concerns from both the scholars and practitioners (Chang and Shaw, 2009; Liu et al., 2015; Pu et al., 2018a). This is especially true for companies in the emerging markets where stand-alone supply chain management software is more favoured over eSCM (Saldanha et al., 2015). Differing from other stand-alone technologies, the value of eSCM can only be reaped when it is co-adopted by more than one supply chain partners (Chan et al., 2012). This interactive nature of eSCM increases uncertainties and risks in supply chains due to reciprocal interdependence and partner synergies (Zhu et al., 2006), which may greatly inhibit eSCM adoption. Implementing eSCM requires companies to transform current transactional relationships into highly interdependent, integrated partnerships. Such interdependency may however encourage partner opportunism because of the challenges to integrate and synchronize the processes, resources and management practices of different companies (Liu et al., 2015). In addition, the power difference between firms further exacerbates the challenges to attain the purported benefits of eSCM. According to resource dependence theory, the dominant company controls scarce and important resources, which grants it with the advantage to exercise its 
power at the expense of the weaker firm (Cai et al., 2013). Therefore, the more powerful company can reap more value from eSCM adoption, which may result in an uneven distribution of benefits that is more favourable to the dominant firm (Ke et al., 2009; Liu et al., 2010). The consequence of implementing eSCM thus is highly unpredictable, which impedes companies from adopting eSCM. The insufficient adoption rate presents a major stumbling block for achieving the vision of a global supply chain (Pu et al., 2018b), which entails more research to better understand the mechanisms underlying eSCM adoption.

While the interactive nature of eSCM urges researchers to shift the firm-level focus to a broader emphasis on the inter-organizational relationships in the supply chain (Liu et al., 2010; Liu et al., 2015; $\mathrm{Pu}$ et al., 2018c), most existing studies have mainly employed theoretical perspectives such as innovation diffusion theory, the RBV, and the transaction cost theory which explain the drivers of eSCM adoption solely from an individual firm's point of view (Liu et al., 2015; Sila, 2015). This narrow theoretical scope is critised to be arbitrary that is insufficient to explain the complexities of eSCM adoption (Sila, 2015). Especially, focusing too much on the static competencies of firms, these frameworks ignore the social and relational factors, which could not take account for the dynamics and interdependencies involved in the adoption process (Liu et al., 2010). As the digital enablers of interfirm collaboration, eSCM relies heavily on socio-technical interactions (Liu et al., 2015). The nature of collaborative relationships, characterized by power and interdependence, thus remains to be a primary constraint in implementing eSCM to achieve successful supply chain integration (Ireland and Webb, 2007; Mora-Monge, 2019). Therefore, the influence of dependency and relational factors on eSCM adoption warrant further investigation.

Considering the abundant results suggesting insignificant relationships between dependence and supply chain management systems adoption in past literature e.g., Chwelos et al. (2001); Huang et al. (2008); Chong et al. (2009b), we propose that the influence of interdependence is translated into a firm's intention to adopt eSCM through information sharing as the mediator. Although the mediation role of information sharing in the relationship between dependency structure and eSCM adoption is not explicitly theorized, it is implicitly demonstrated in the extant literature that information sharing serves as one important link between dependency structure and eSCM adoption. It is widely acknowledged that information sharing is one of the key outcomes of dependency structure (Patnayakuni et al., 2006; Vijayasarathy, 2010; Yigitbasioglu, 2010), and information sharing is also regarded as a significant antecedent of eSCM adoption (Chong et al., 2013; Chong and Bai, 2014). 
This study aims to investigate the effects of dependency structure and mediating role of information sharing in the relationship between interdependence and eSCM adoption. Drawing on the structural embeddedness theory and resource dependence theory, we investigate the influence of three different dimensions of dependence - dependence advantage, dependence disadvantage and mutual dependence, and the moderating effect of one key supply chain relationship characteristic - relationship duration. Our findings develop a granular understanding of the mechanisms underlying eSCM adoption.

\section{Literature Review and Theoretical Background}

\subsection{Electronic Supply Chain Management}

eSCM coordinates the supply chain operations across trading partners with the support of Webbased technologies (Liu et al., 2010; Chong and Bai, 2014; Liu et al., 2015; Zhou et al., 2018). Different from traditional stand-alone supply chain management technologies, only when eSCM has been adopted by two or more supply chain partners can its value be achieved (Chan et al., 2012).The reciprocal interdependence and partner synergies involved in eSCM could exacerbate uncertainties and risks in supply chains (Zhu et al., 2006), thereby restraining eSCM adoption. Thus, the inter-organizational relationships among supply chain partners and the interdependence structure involved are likely to play important roles in explaining the complexity of eSCM adoption.

Current studies on the adoption of eSCM increasingly highlight the interactive nature of eSCM and broaden their focus to the inter-organizational relationships in the supply chain. For example, Liu et al. (2010); Saldanha et al. (2015) have investigated the effects of institutional pressures affect firms' eSCM adoption. Extant study also investigated the influence of relational factors, including power and trust of the firms in the inter-organizational relationships in the supply chain, on firm's intention to adopt eSCM (Liu et al., 2015; Saldanha et al., 2015; Mora-Monge, 2019) . In addition, Wu and Chuang (2010) and Zhou et al. (2018) consider collaborative relationship among trading partners as the key antecedent to eSCM diffusion. These extant studies concerning the adoption of inter-organizational information systems have mainly employed theoretical frameworks such as the Diffusion of Innovation theory, the Technology-Organization-Environment (TOE) model, the Technology Acceptance Model, and the Transaction Cost Theory to investigate eSCM adoption (Liu et al., 2010; Wu and Chuang, 2010; Chan et al., 2012). However, the traditional frameworks are becoming less relevant for contemporary supply chain management systems (Pu et al., 2018b). For example, compatibility and complexity are less concerned by practitioners with the wider application of 
Extensible Markup Language (XML) and the public internet (Chong et al., 2013). In addition, the traditional paradigms commonly assume that companies are independent, self-sustaining units that make decisions solely based on a single firm's point of view (Pu et al., 2016), which however ignores that the open and collaborative nature of eSCM can make the potential benefits from adoption dependent on other partners (Zhao et al., 2007). The adoption of eSCM is therefore highly uncertain with the involvement of various parties, which suggests the significance of examining the role of the interdependency and inter-organizational relationships in a firm's behavioural intention. Hence, this study goes beyond the traditional frameworks by drawing on the Resource Dependency Theory (RDT) to enhance the understanding of the influence of network factors on the adoption intention of eSCM.

\subsection{Resource Dependency Theory and Dependence Structure}

It is the central proposition of Resource Dependency Theory (RDT) that an organization's survival is determined by its ability to obtain scarce resources from the external environment (Pfeffer and Salancik, 1978). To reduce the uncertainty associated with critical resource flows, organizations have to employ a wide variety of strategies to reduce their dependence on external resources, or, where possible, to influence the environment to create greater resource availability. Therefore, an organization's dependence on external resources is a significant determinant of its actions and behaviours. RDT is suggested to have considerable explanatory power for a wide spectrum of organizational behaviours. This study thus employs RDT as an appropriate theoretical lens to investigate organizational intentions and behaviours towards eSCM adoption.

The seminal work of Emerson (1962) defines dependence as a function of resource criticality and the availability of alternative resources. Emerson (1962) emphasizes the structural dichotomy of dependence, and distinguishes between the concepts of interdependence and dependence asymmetry (Casciaro and Piskorski, 2005). Interdependence is referred to as the level of bilateral dependence between two actors, which can be measured as the sum or the product of the dependence that two actors have on each other. A firm and its partners are interdependent to the extent that the dependence of the firm on its partners is high and simultaneously the dependence of the partners on the firm is high. Dependence asymmetry, on the other hand, captures the power difference of two actors over each other. The term "power advantage" is used by Emerson (1962) to distinguish the directionality of power asymmetry, which can identify which side of a relationship obtains more power. When a firm's partners are more dependent on the firm, the partners' excess dependence formulates the firm's dependence 
advantage. Conversely, when a firm is more dependent on its partners, its net dependence is positive, which constructs its dependence disadvantage (Gulati and Sytch, 2007).

Most studies investigating the influence of power and dependence, especially in the context of supply chain management systems adoption, failed to make explicit distinctions between interdependence and dependence asymmetry. Much work so far has focused on the unidirectional dependence of one actor on another, whereas scant attention has been paid to the reciprocal interdependence between two parties, e.g., Huang et al. (2008), Zhang and Dhaliwal (2009), Chong et al. (2009a), and Chan et al. (2012). These studies thus ignored that the effects of dependence asymmetry and interdependence occur through different logics of action and affect organizational behaviours in different ways (Gulati and Sytch, 2007). To comprehensively delineate dependency structure, it is imperative to consider both concepts (i.e., interdependence and dependence asymmetry) at the same time (Casciaro and Piskorski, 2005; Gulati and Sytch, 2007).

In the extant literature, there have been abundant empirical results showing an insignificant relationship between dependence and the adoption of eSCM have shown that, e.g., Chwelos et al. (2001); Huang et al. (2008); Chong et al. (2009b). This could suggest that dependence structure might not have a direct effect on eSCM adoption. It is suggested that dependency patterns will impact a firm's supply chain practices (Lusch and Brown, 1996), which in turn facilitates eSCM adoption. Therefore, we propose that the relationship between dependence structure is mediated by information sharing in the supply chain. Information sharing is a critical mechanism to alleviate supply chain uncertainty by sharing information availability about demand and supply (Li et al., 2006). Therefore, dependence structure in the supply chain will affect information sharing behaviours and motivate companies adopt eSCM in order to create better information availability.

\subsection{Information Sharing}

Information sharing is the mutual sharing of operational, marketing and logistics information in supply chain networks. Information sharing is considered as the generic cure for problems associated with supply chain management (Sahin and Robinson, 2002). Information asymmetry is a critical problem faced by many market participants. Imperfect information about demand and supply can lead to great uncertainty in the supply chain. To cope with uncertainty, it is of strategic importance to improve information availability and enhance communication channels ( $\mathrm{Li}$ et al., 2006). Improved information sharing capability is shown to be positively associated with supply chain performance (Kulp et al., 2004; Rai et al., 2006). 
Although the mediation role of information sharing between dependency structure and eSCM adoption is not explicitly theorized, it is implicitly demonstrated in the extant literature that information sharing serves as one important link between dependence structure and eSCM adoption. It is widely acknowledged that information sharing is one of the key outcomes of network embeddedness (Burt, 1997; Uzzi, 1997; Adler and Kwon, 2002) and dependency structure (Patnayakuni et al., 2006; Vijayasarathy, 2010; Yigitbasioglu, 2010), and is also regarded as a significant antecedent of eSCM adoption (Chong et al., 2013; Chong and Bai, 2014). It is shown that forming network ties could foster the sharing of complex and tacit information and knowledge (Hansen, 1999). With network embeddedness, firms are able to exchange granular information (Uzzi, 1997), and the social capital resulted from network embeddedness could encourage information exchange activities among business partners (Burt, 1997; Wu, 2008). In addition, studies based on RDT have shown that dependence structure might have a direct effect on how and what information is shared (Patnayakuni et al., 2006; Vijayasarathy, 2010; Yigitbasioglu, 2010). Therefore, this study is going to investigate the role of information sharing in the relationship between dependence structure and eSCM adoption.

\section{Hypothesis Development}

\subsection{Dependence Structure and Information Sharing}

The structural patterns of interdependence can explain the emergence of a firm's motive for relationship development (Murray et al., 1996). When the power of one party is greater than another party, the weak party would be more willing to devote efforts to elevate the relationship with the powerful party (Buchanan, 1992). The disadvantaged firm would also be more committed to the relationship and exhibit greater long-term orientation (Murray et al., 1996). The weak firm thus is more inclined to enhance information sharing in the supply chain network to facilitate collaboration.

When a firm is unilaterally dependent on its partner, information sharing will be preferred as an efficient mechanism to mitigate supply chain risk (Lavastre et al., 2014). The shared information could act as a relationship safeguard and commitment ensuring the continuance of the relationship with the powerful partner. The weak party in a supply chain network, therefore, would have greater willingness to enhance information sharing for the purpose of sustaining its access to the partner's resources (Buchanan, 1992). We therefore propose that:

H1: The more a firm is dependent on its partners (i.e., dependence disadvantage), the more the firm is willing to enhance information sharing. 
When a firm obtains power over its weak partner, it would be less likely to maintain the relationship (Buchanan, 1992). A disadvantaged partner is generally considered to be of low value. The powerful company will thus have little incentive to share information with weaker partners because of low return. In asymmetric dependence structure, the party that is more powerful is endowed with the advantage of appropriating value from the relationship (Ghadge et al., 2017). The powerful firm can take tactics that are adversarial to its weak partner and the chance of retaliation is slender. The more dominant partner thus can leverage its power to free ride the information acquired from the weaker partner but refuse to exchange information in a reciprocal manner (Lusch and Brown, 1996; Wu, 2008). To minimize potential switching cost and gain supply chain flexibility, the powerful firm will be unwilling to establish formal communication mechanism regardless of the plea from the weak partner for relationship enhancement. We therefore make the following hypothesis:

H2: The more a firm's partners are dependent on the firm (i.e., dependence advantage), the more the firm is willing to enhance information sharing.

When the dependence structure is symmetric (i.e., interdependence), both parties have a large stake in the existing relationship. The vested interests will motivate both sides to engage in collective actions for joint payoff (Lusch and Brown, 1996). In addition, high interdependence will promote the sense of recognition between the partners, leading to a convergence of values and goals (Mizruchi, 1989). Interdependent partners, therefore, are more likely to develop empathy for each other and work for bilateral success (Gulati and Sytch, 2007). With long-term orientation, it will be more likely for the partners to achieve mutual agreement to enhance interfirm communication and collaboration (Ming et al., 2014). The mutual commitment and long-term orientation could function as non-contractual governance mechanism to mitigate the risk of information free-riding and therefore encourage the sharing of business and operational information ( $\mathrm{Wu}, 2008)$. Interdependent partnerships also foster relational trust which creates a favourable environment for information sharing by enhancing information disclosure and granting knowledge access in the supply chain network. It is therefore more likely that open and honest information sharing in interdependent partnerships thus can information sharing and coordination (Rai and Tang, 2010). Thus we posit the following hypothesis:

H3: The greater the interdependence between a firm and its partners, the more the firm is willing to enhance information sharing. 


\subsection{Information Sharing and eSCM Adoption}

It is indicated that increasing the level of information sharing with the partners is the key to improve the competitiveness and effectiveness of a supply chain (Lin et al., 2002; Sezen, 2008). Information sharing is a cooperative behaviour by trading partners to enable quick and accurate exchange of critical or proprietary information (Sezen, 2008). The significance of information sharing has been extensively confirmed in the literature. It is reported that, for example, sharing supply and demand information can help reduce inventory cost and shorten order cycle time (Lin et al., 2002). A company is also better equipped to deal with the volatilities of demand and the turbulences in business environment when information is shared seamlessly (Lee et al., 2000).

Implementing eSCM can greatly improve a firm's information sharing ability. With eSCM, a firm can exchange technical knowledge and rich content information about inventory and product design (Ke et al., 2009). Real-time information sharing and active coordination can also be attained by eSCM, through which supply chain members can respond more promptly to market fluctuations (Liu et al., 2010). Employing eSCM can also dramatically reduce the costs associated with communication, and thus enhance the benefits of information sharing. Therefore, when a firm expect to increase the level of information sharing, it would be proactive towards the adoption of eSCM:

H4: The more a firm is willing to enhance information sharing, the greater is the firm's intention to adopt eSCM.

\subsection{The moderating effect of relationship duration}

Except for dependence structure, the characteristics of inter-organizational relationships are also important aspects of network structures. Especially, we focus on the effect of relationship duration which is a fundamental characteristic of a firm's supplier portfolio. Relationship duration indicates the average period of time a company has been interacting with its major suppliers (Tang and Rai, 2012). The length of trading relationships can range from very shortterm, arm's length to closely coordinated long-term, which will affect a firm's decision on the implementation of supply chain management systems (Shah et al., 2002).

The length of a relationship can be used as a proxy for relational strength and depth (Uzzi, 1997). The longer the duration of a trading relationship, the stronger the relationship is, and the greater the chance that the trading parties have shared a common understanding and engaged in joint actions to reduce coordination cost (Coleman, 1990). Although the mutual 
understanding and commitment in long-term relationship may directly encourage the adoption of eSCM for better collaboration, the well-established communication routines and practices in long-term relationship could serve as effective information exchange channels and therefore may to some extent reduce a firm's need for information sharing. Thus the positive effect of information sharing on eSCM adoption could be curbed by existing collaboration and communication mechanisms developed in long-term relationships. The longer the collaborative relationships, the more effective and mature the existing communication channels will be, and the less likely a firm will be motivated to adopt eSCM by the willingness to enhance information sharing. We therefore suggest the following hypothesis on the moderating role of relationship duration:

H5: Relationship duration negatively moderates the effect of information sharing on a firm's intention to adopt eSCM.

\subsection{Indirect effect of interdependence on eSCM Adoption}

Considering the abundant results suggesting insignificant relationships between dependence and supply chain management systems adoption in past literature e.g., Chwelos et al. (2001); Huang et al. (2008); Chong et al. (2009b), we propose that the influence of interdependence, rather than directly affecting eSCM adoption, is mediated by information sharing. It is suggested that dependency patterns will impact a firm's relational intentions and behaviours (Lusch and Brown, 1996), which in turn affects eSCM adoption. This line of reasoning suggests that the intention to share information encouraged by interdependence can further enhance a firm's intention to adopt eSCM.

Sharing information is bidirectional that emphasizes the mutual efforts by both sides of a relationship. This reciprocal nature of information sharing is consistent with the mechanism of interdependence which emphasizes social norms and commitment. When the supply chain partners are interdependent, they tend to maintain frequent interfirm interaction that involves multiple organizational layers (Johnson and Sohi, 2001). This healthy routine of communication developed in close collaboration can improve the benefits of information sharing (Mohr and Sohi, 1995), thus will further stimulate the intention of adopting eSCM. In addition, a firm's willingness to share information might be restricted by the concerns about exposing business secrets if its partners act opportunistically, which may constrain the influence of information sharing on eSCM adoption. Interdependence creates a mutual confidence that the exchanged partners will not exploit the vulnerabilities of the others, which 
reduce the risk of information sharing and therefore motivate the adoption of eSCM (Moberg et al., 2002). Furthermore, the social capital generated in interdependent relationships can enhance the efficiency of information searching and the sharing of valuable information, which could facilitate the efficiency of sharing information through eSCM. These arguments suggest the following hypothesis on the indirect effect of independence on eSCM adoption:

H6: The relationship between information sharing and the intention to adopt eSCM is mediated through interdependence such that greater willingness for information sharing developed through interdependence will increase the intention to adopt eSCM.

To summarize, the conceptual model of this research is illustrated in Figure 1.

$<$ Insert Figure 1 around here $>$

\section{Research Design}

\subsection{Data Collection}

An online questionnaire was developed to collect data in the Mainland China to test the proposed hypotheses. We distributed the questionnaire in the Shenzhen Anti-Counterfeiting Association (SACA) which is a government supported non-profit association of companies aiming at combating counterfeiting and ensuring product quality. A key informant helped us distribute the questionnaire among the members of SACA through email. A cover letter by the key informant was attached with the email to increase response rate. The data collection process lasted for four weeks spanning from the second week of March 2017 to the second week of April 2017. A reminder email was sent in the first week of April 2017, two weeks after we sent the first email, to facilitate response. In total, there were 397 attempted responses and 212 of them were valid for analysis (53.4\% completion rate). The demographic information of the data is demonstrated in Table 1.

$<$ Insert Table 1 around here $>$

\subsection{Construct Measurement and Questionnaire Development}

Whenever possible, existing measurements in the literature were adapted from past studies to safeguard the content validity of the constructs and their fit in the research context, and to ensure that the overlap among the constructs was minimal (Cronbach, 1971; Kerlinger, 1986). The key variables in this study were operationalized as multi-item constructs. To decide whether a construct should be modelled as formative or reflective, four major criteria should be examined: (1) the direction of causality between constructs and their indicators, (2) the 
interchangeability of indicators, (3) the covariation among indicators, and (4) the nomological net of constructs (Jarvis et al., 2003). A latent variable should be constructed as formative when the direction of causality is from the indicators to the constructs (i.e., the indicators create the constructs), the indicators are not inter-changeable and do not necessarily covary, and the nomological net of the indicators can differ (Chin, 1998). In contrast, reflective constructs should be created when the opposite conditions hold: the direction of causality is from the constructs to the indicators (i.e., the indicators are caused by the constructs), and the indicators are interchangeable and necessarily covary. Suggested by the decision rules, all the multi-item dependent and independent variables in the research model are modelled as reflective, and the mediation variable information sharing is modelled as formative.

Dependent Variable. Adoption intention is a reflective construct adapted from Son and Benbasat (2007) and Liu et al. (2010), which measures the estimation of the respondents about whether their companies would actually adopt eSCM in the foreseeable future.

Independent Variables. Dependence disadvantage and dependence advantage are specified as reflective constructs which, respectively, measure the extent to which a firm is dependent on its major partners and the extent to which a firm's major partners are dependent on the firm. For interdependence, a firm and its partners are interdependent to the extent that the dependence of the firm on its partners is high and simultaneously the dependence of the partners on the firm is high. Therefore, following Casciaro and Piskorski (2005), interdependence is measured as the interaction term of dependence disadvantage and dependence advantage.

Mediation Variable. Information sharing measures the expectation of a firm to exchange critical and proprietary information with its supply chain partners about the demand and supply for the management of production controlling and planning, and it is specified as a formative construct with three items.

Moderation Variable. Relationship duration is measured by asking the respondents to provide the average length (in years) of the relationships between its firm and its major partners.

Dependence disadvantage, dependence advantage and information sharing are measured by seven-point Likert scales with 1 representing strongly disagree and 7 representing strongly agree. The definitions and the sources of all the constructs are summarized in Table 2. The survey items employed to measure these constructs are presented in Appendix.

$<$ Insert Table 2 around here $>$ 
Control Variables. The control variable industry type is coded as a dummy variable with 1 representing the manufacturing industry and 0 representing the service industries. Following Liu et al. (2010), the retail/wholesale, bank/insurance, transport/distribution, and other services are categorized as service industry based on the principle that whether a firm manufactures physical products or provides intangible services (Mitra and Singhal, 2008). For organization type, dummy variables are created to indicate whether a firm is state-owned, privately owned, or foreign-controlled. The number of years a firm has been operating could also affect the intention to adopt eSCM as older firms are more likely to own legacy systems that might reduce their intention to adopt new information systems. We also control for firm size by measuring the yearly turnover of a firm.

\section{Data Analysis}

\subsection{Measurement Validation}

To assess the construct validity and the unidimensionality of the multi-item measurement scales, Exploratory Factor Analysis (EFA) and Confirmatory Factor Analysis (CFA) are conducted. As shown in Table 3, the factor loadings for all indicators exceed the recommended value of 0.60 . All the average variance extracted (AVE) were above the critical value of 0.5 , suggesting that the explained variance by the indicators of each construct is more than the variance unexplained. The CFA analysis further reveals $\chi^{2} / \mathrm{df}=2.25$, Root Mean Square Error of Approximation $($ RMSEA $)=0.077$, Comparative Fit Index $(\mathrm{CFI})=0.959$, Normed Fit Index $(\mathrm{NFI})=0.929$, Parsimony Goodness of-Fit Index $(\mathrm{PGFI})=0.538$, and Parsimony Normal Fit Index $(\mathrm{PNFI})=$ 0.642 , indicating a good model fit.

\section{$<$ Insert Table 3 around here $>$}

As shown in Table 4, discriminant validity is supported as the square root of the average variance extracted for each latent factor (figures on the diagonal) are larger than the respective correlations between the factors (Fornell and Larcker, 1981). In addition, in Table 3 it shows that composite reliabilities, which reflect the degree to which the indicators explain the constructs, are all above the recommended threshold of 0.8 and the Cronbach's Alphas all exceed the suggested critical value of 0.7 (Fornell and Larcker, 1981), demonstrating adequate convergent validity. 


\subsection{Common Method Bias and Response Bias}

Because the data were collected from one informant at a single point of time, it is critical to ensure that common method bias would not be a threat to the validity of the results. Following Liu et al. (2010), we tested for common method variance (CMV). A three-item construct partner opportunism - was identified a priori to be theoretical unassociated with the dependent variable and was selected as the method variance (MV) marker to adjust the correlations. The smallest positive correlation between the CMV marker and the dependent variable $(r=0.004$, Table 4) was chosen as the estimate of the CMV adjustment (Lindell and Whitney, 2001). As reported in Table 4, the correlations that were statistically significant before the adjustment remained to be significant, suggesting that it is unlikely the validity of the results is contaminated by CMV.

We concerned that the data might be subject to noncontingent response bias (NCR) if the respondents provided random or careless answers (Baumgartner and Steenkamp, 2001). Therefore, a NCR index was generated following the procedures of Baumgartner and Steenkamp (2001). Firstly, seven pair of items that are the mostly correlated, have the similar means, and are scored in the same direction were selected. The average inter-correlation of the selected pairs was 0.708 , ranging from 0.638 to 0.754 . The NCR index was then formulated as the sum of the absolute differences between the paired items. The underlying logic behind NCR is that highly correlated items are highly homogeneous in content thus should have consistent answers. Large absolute differences between the pair items might imply the chance that the data are jeopardized by erratic response style.

\subsection{Hypothesis Testing}

Our theoretical model (see Figure 1) implies a moderated mediation relationship because the postulated mediated effect of interdependence on eSCM adoption through information sharing is moderated by relationship duration. The following system of equations is developed to evaluate the empirical support for our hypotheses (Preacher et al., 2007):

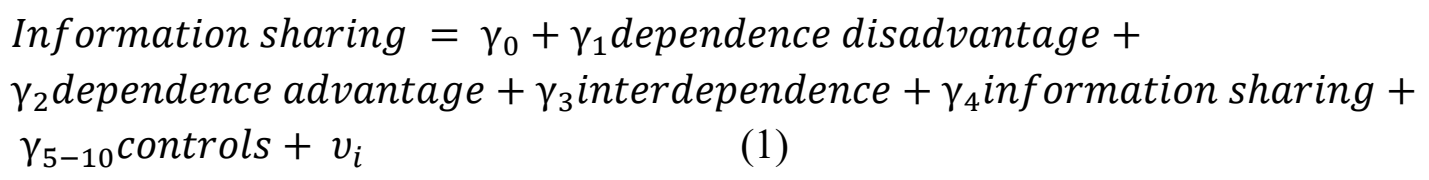

to obtain

information sharing residual $_{\text {information sharing }-}$ information sharing predicted 
Adoption intention $=\beta_{0}+\beta_{1}$ information sharing ${ }_{\text {residual }}+\beta_{2}$ interdependence + $\beta_{3}$ relationship duration $+\beta_{4}\left(\right.$ information sharing ${ }_{\text {residual }} \times$ interdependence $)+$ $+\beta_{5-10}$ controls $+e_{i}$

Conventional analytical methods such as ordinary least squares (OLS) and general least squares (GLS) might not be appropriate for this study because the endogenous variable - information sharing - is also specified as the explanatory variable of another equation in the system (Hamilton and Nickerson, 2003; Wooldridge, 2010). Specifically, we first obtained the residuals of information sharing as a function of the independent variables listed in equation (1). The obtained residual was then used as the indicators of information for estimating regression parameters in equation (2). The three-stage least squares (3SLS) estimation, which combines the features of two-stage least squares (2SLS) and seemingly unrelated regression estimation (SURE), was employed to analyse data to simultaneously address the problems of dependent repressors and correlation of error terms (Kuruzovich et al., 2008). In addition, 3SLS is recommended to be a more efficient approach (compare with OLS and GLS) to solve triangular structural models (Lahiri and Schmidt, 1978), just as the research model proposed in this study. Furthermore, because our research model involves interaction effects, using 3SLS can cater for interacting variables in easier manners compared with structural equation modelling (SEM). To avoid multicollinearity issues, all the independent variables were grand mean centered (Aiken and West, 1991).

We subsequently evaluate whether information sharing mediates the impact of interdependence on eSCM adoption intention by applying the bootstrap approach to 3SLS estimation (Salvador et al., 2014). The details will be explained in in the next section.

\subsection{Direct and moderation effects}

As shown in Table 5, regarding the effects of the dependence structure, we found support for hypothesis $\mathrm{H} 1$ which proposes that dependence disadvantage (beta $=0.195, \mathrm{p}<0.05$ ) to be positively related with information sharing. Hypothesis $\mathrm{H} 2$, which proposes that dependence advantage is negatively related with information sharing, was not supported by the result (beta $=0.067, \mathrm{~ns})$. Evidence was also found to support hypothesis $\mathrm{H} 3$ which showed a positive effect of interdependence (beta $=0.150, \mathrm{p}<0.05$ ) on information sharing.

Information sharing (beta $=0.304 . \mathrm{p}<0.01$ ) was found to have a strong positive relationship with adoption intention, which provides support for hypothesis H4. The negative moderation 
effect of relationship duration (beta $=0.151, \mathrm{p}<0.05$ ) was found on the relationship between information sharing and adoption intention, supporting hypothesis H5.

$<$ Insert Table 5 around here $>$

\subsection{Mediation effects}

Hypothesis 6 suggests that effect of interdependence on eSCM adoption is mediated through information sharing. Given the moderated-mediation nature of our model, the conditional indirect effect of interdependence on eSCM adoption equals to $\gamma_{3} *\left(\beta_{1}+\right.$ $\beta_{4}$ relationship duration), and needs to be evaluated at different levels of relationship duration (Preacher et al., 2007). Therefore, we obtained the $95 \%$ confidence interval for the conditional indirect effects of interdependence on adoption intention at low, mean, and high values of relationship duration. According to Preacher et al. (2007), support for the indirect effect of interdependence on eSCM adoption through information sharing is supported when the $95 \%$ confidence interval does not include zero. As shown in Table 6 , the $95 \%$ confidence intervals for the effect of interdependence on eSCM adoption did not include zero for low and mean levels of relationship duration, while the confidence interval included zero when relationship duration is high. Furthermore, the results of 3SLS estimation (Table 5 Panel B) suggests that information sharing and information sharing * relationship duration are significantly associated with $\mathrm{eSCM}$ adoption, while the effect of interdependence is not statistically significant. To summarize, these results suggest that the effect of interdependence on eSCM adoption is fully mediated through information sharing when relationship duration is either below or about the mean. No mediation relationship through information sharing was found, however, when relationship during is high. This result is consistent with the moderation effect of relationship duration suggesting that the effect of information sharing is muted as relationship during increases. Based on the results, we conclude that H6 is supported.

$<$ Insert Table 6 around here $>$

\section{Discussion and Implications}

\subsection{Theoretical Implications}

This research extends the understanding of the adoption of eSCM by investigating the influence of the structural patterns of interdependence, the contextual characteristic of supply chain relationship (relationship duration) and information sharing. This study reveals the importance of the network structures and the significance of resource dependence theory as promising paradigm to study inter-organizational information systems. By exploring the bidirectional 
nature of dependence, this study provides a granular understanding of how the direction of dependence could yield variant effects on supply chain practices. The findings fill in the gap in current research where there has been a salient focus on the less powerful actors (e.g., dependence on partners) while the more powerful actors have been rarely discussed and empirically studied.

Consistent with our hypotheses, dependence disadvantage yields positive effects on information sharing. A company thus would be willing to share information with the dominant partners to manage or attenuate external uncertainties even though their partners could capture more benefits from the shared information. Interdependence also plays a significant role in enhancing a firm's willingness for information sharing. The sharing of information is a bidirectional collaborative behaviour which requires the devotion from both sides of a relationship. The findings confirm the logic of embeddedness which suggests joint achievements in high quality relationships. Interdependent partners are driven by hared understanding and goals, mutual empathy, and trust to make joint efforts that increase the collaboration and communication in their collaborative relationships. However, no evidence was found to support the negative effect of dependence advantage. Although dependence advantage can endow a firm with the power to occupy more benefits from increased information sharing, developing communication channels would also mean the unavoidable increase in relation-specific assets, which could consequently increase the dominant firm's dependence on weak partners (Buchanan, 1992; Gounaris, 2005). Therefore, the attraction of reaping the benefits of information sharing would be not be adequately enough for a dominant firm to sacrifice its valuable dependence advantage (Geiger et al., 2012).

Relationship duration is found to negatively moderate the relationship between information sharing and a firm's intention to adopt eSCM. This finding implies that in long-term relationships, partners might have already established effective communication channels, which will reduce the importance of implementing new digital channels to share supply chain information. This negative moderation effect of relationship duration also shed light on the possible effect of path dependency in the process of adopting eSCM (Zhu et al., 2006). The information sharing practices developed in long-term inter-firm relationships may hinder firm from adopting eSCM even though that eSCM provides a more efficient mechanism to share information.

One of the key aims of this study is to investigate the mediation role of information sharing in the relationship between dependence structure and eSCM adoption. We find that 
interdependence will have positive effect on a firm' intention to adopt eSCM while lacking a direct effect. The results lend support to the theoretical arguments that information sharing is one of the key outcomes of dependency structure (Patnayakuni et al., 2006; Vijayasarathy, 2010; Yigitbasioglu, 2010), and is also a significant antecedent of eSCM adoption (Chong et al., 2013; Chong and Bai, 2014). A firm that is interdependent with its partners will be more willing to share information in the supply chain, which will motivate this firm to adopt eSCM because it could enhance the firm's information sharing ability. To this end, interdependence and interfirm relationships alone cannot motivate eSCM adoption. Rather, they create the need for information sharing and stimulate a firm to adopt eSCM to improve information efficiency. This finding provides the theoretical implication suggesting that interdependence might be necessary but insufficient conditions for companies to adopt eSCM. In addition, the mediation effect of information sharing is broadly supported by the results which shows that information sharing fully mediates the relationship between interdependence and the intention to adopt eSCM when the length of relationship duration is below or at the mean. This provides support for the impact of interdependence on eSCM adoption, but that this effect is attenuated with increase in relationship duration. These findings offer an explanation for the inconclusive empirical results of the relationship between interdependence and ESCM adoption in the extant literature.

\subsection{Practical Implications}

The findings of this research provide important implications for industry practitioners to better understand the factors and conditions that affect the diffusion of eSCM. Our findings have highlighted the importance of interdependence and information sharing in affecting the adoption intention of eSCM. Firms considering adopting eSCM should assess the extent to which they and their partners are interdependent and their needs for information sharing are affected by the levels of interdependence. Firms that are interdependent with their suppliers are more prone to enhance information sharing in the supply chain and thus have greater intention to adopt eSCM. Therefore, for firms that are interdependent with their partners, the practitioners should specifically promote the ability to improve inter-organizational information sharing as a salient feature of eSCM. The practitioners may also need to evaluate the characteristics of a firm's supply chain relationship.

Firms that have been maintaining long-term relationships with their partners need to assess benefits and costs of adopting eSCM. As shown by our results, these firms may not have strong needs for information sharing because they have already established effective information 
sharing mechanisms. Therefore, for these firms, the improvement in information sharing efficiency may not be sufficient to justify the costs of implementing eSCM. It is very important for these firms to carefully evaluate their current information availability and communication channels before they make the decision to implement eSCM.

\section{Limitations and Future Research}

First, this research focuses on the adoption intention rather than the actual adoption level. Although estimation measure could provide prediction of better performance (Sheppard et al., 1988), adoption intention may not be able to reflect the nomological net for actual adoption (Liu et al., 2010). Future research therefore can measure the actual adoption level of eSCM and analyze its relationships with the factors developed from embeddedness theory. Second, our data is collected from China where there is a collectivist cultural environment and therefore the respondents may have a tendency to agree regardless of the content of the questions (Liu et al., 2010). Thus there might be a slight chance of acquiescence bias in our data.

\section{References}

Adler, P. S. and Kwon, S.-W. (2002) "Social capital: Prospects for a new concept", Academy of management review, 27(1), pp. 17-40.

Aiken, L. S. and West, S. G. (1991) Multiple Regression: Testing and Interpreting Interactions. Newbury Park, CA: Sage.

Baumgartner, H. and Steenkamp, J.-B. E. M. (2001) "Response Styles in Marketing Research: A Cross-National Investigation", Journal of Marketing Research, 38(2), pp. 143156.

Buchanan, L. (1992) "Vertical Trade Relationships: The Role of Dependence and Symmetry in Attaining Organizational Goals", Journal Of Marketing Research, 29(1), pp. 65-75.

Burt, R. S. (1997) "The contingent value of social capital", Administrative science quarterly, pp. 339-365.

Cai, S., Goh, M., de Souza, R. and Li, G. (2013) "Knowledge sharing in collaborative supply chains: twin effects of trust and power", International Journal of Production Research, 51(7), pp. 2060-2076.

Casciaro, T. and Piskorski, M. (2005) "Power Imbalance, Mutual Dependence, and Constraint Absorption: A Closer Look at Resource Dependence Theory", Administrative Science Quarterly, 50(2), pp. 167-199.

Chan, F. T. S., Chong, A. Y.-L. and Zhou, L. (2012) "An Empirical Investigation of Factors Affecting E-Collaboration Diffusion in SMEs", International Journal of Production Economics, 138(2), pp. 329-344. 
Chang, H.-L. and Shaw, M. J. (2009) "The Business Value of Process Sharing in Supply Chains: A Study of RosettaNet", International Journal of Electronic Commerce, 14(1), pp. 115-146.

Chin, W. W. (1998) 'The partial least squares approach to structural equation modeling', in Marcoulides, G.A. (ed.) Modern methods for business research. Mahwah, NJ: Lawrence Erbaum Associates, pp. 295-336.

Chong, A. Y.-L. and Bai, R. (2014) "Predicting Open IOS Adoption in SMEs: An Integrated SEM-Neural Network Approach", Expert Systems with Applications, 41(1), pp. 221-229.

Chong, A. Y.-L., Chan, F. T. S., Goh, M. and Tiwari, M. K. (2013) "Do Interorganisational Relationships and Knowledge-Management Practices Enhance Collaborative Commerce Adoption?", International Journal of Production Research, 51(7), pp. 2006-2018.

Chong, A. Y.-L., Ooi, K.-B., Lin, B. and Yi Tang, S. (2009a) "Influence of interorganizational relationships on SMEs' e-business adoption", Internet Research, 19(3), pp. 313-331.

Chong, A. Y.-L., Ooi, K.-B. and Sohal, A. (2009b) "The Relationship Between Supply Chain Factors and Adoption of E-Collaboration Tools: An Empirical Examination", International Journal of Production Economics, 122(1), pp. 150-160.

Chwelos, P., Benbasat, I. and Dexter, A. S. (2001) "Research Report: Empirical Test of an EDI Adoption Model", Information Systems Research, 12(3), pp. 304-321.

Coleman, J. S. (1990) Foundations of Social Theory. Cambridge, MA: Harvard University Press.

Cronbach, L. J. (1971) 'Test Validation', in Thorndike, R. (ed.) Educational Measurement. 2nd ed. Washington, DC: merican Council on Education, pp. 443-507.

Emerson, R. M. (1962) "Power-Dependence Relations", American Sociological Review, 27(1), pp. 31-41.

Fornell, C. and Larcker, D. F. (1981) "Evaluating Structural Equation Models with Unobservable Variables and Measurement Error", Journal of Marketing Research, 18(1), pp. 39-50.

Geiger, I., Durand, A., Saab, S., Kleinaltenkamp, M., Baxter, R. and Lee, Y. (2012) "The bonding effects of relationship value and switching costs in industrial buyer-seller relationships: An investigation into role differences", Industrial Marketing Management, 41(1), pp. 82-93.

Ghadge, A., Dani, S., Ojha, R. and Caldwell, N. (2017) "Using risk sharing contracts for supply chain risk mitigation: A buyer-supplier power and dependence perspective", Computers \& Industrial Engineering, 103, pp. 262-270.

Gounaris, S. P. (2005) "Trust and commitment influences on customer retention: insights from business-to-business services", Journal of Business Research, 58(2), pp. 126-140. 
Gulati, R. and Sytch, M. (2007) "Dependence Asymmetry and Joint Dependence in Interorganizational Relationships: Effects of Embeddedness on a Manufacturer's Performance in Procurement Relationships", Administrative Science Quarterly, 52(1), pp. 32-69.

Hamilton, B. H. and Nickerson, J. A. (2003) "Correcting for Endogeneity in Strategic Management Research", Strategic Organization, 1(1), pp. 51-78.

Hansen, M. T. (1999) "The Search-Transfer Problem: The Role of Weak Ties in Sharing Knowledge across Organization Subunits", Administrative Science Quarterly, 44(1), pp. 82111.

Huang, Z., Janz, B. D. and Frolick, M. N. (2008) "A Comprehensive Examination of InternetEDI Adoption", Information Systems Management, 25(3), pp. 273-286.

Ireland, R. D. and Webb, J. W. (2007) "A multi-theoretic perspective on trust and power in strategic supply chains", Journal of Operations Management, 25(2), pp. 482-497.

Jarvis, C. B., MacKenzie, S. B. and Podsakoff, P. M. (2003) "A Critical Review of Construct Indicators and Measurement Model Misspecification in Marketing and Consumer Research", Journal of Consumer Research, 30(2), pp. 199-218.

Johnson, J. L. and Sohi, R. S. (2001) "The influence of firm predispositions on interfirm relationship formation in business markets", International Journal of Research in Marketing, 18(4), pp. 299-318.

Ke, W., Liu, H., Wei, K. K., Gu, J. and Chen, H. (2009) "How Do Mediated and NonMediated Power Affect Electronic Supply Chain Management System Adoption? The Mediating Effects of Trust And Institutional Pressures", Decision Support Systems, 46(4), pp. 839-851.

Kerlinger, F. N. (1986) Fundamentals of Behavioral Research. Rinehart\&Winston.

Kulp, S. C., Lee, H. L. and Ofek, E. (2004) "Manufacturer benefits from information integration with retail customers", Management science, 50(4), pp. 431-444.

Kuruzovich, J., Viswanathan, S., Agarwal, R., Gosain, S. and Weitzman, S. (2008) "Marketspace or marketplace? Online information search and channel outcomes in auto retailing", Information Systems Research, 19(2), pp. 182-201.

Lahiri, K. and Schmidt, P. (1978) "On the Estimation of Triangular Structural Systems", Econometrica, 46(5), pp. 1217-1221.

Lavastre, O., Gunasekaran, A. and Spalanzani, A. (2014) "Effect of firm characteristics, supplier relationships and techniques used on Supply Chain Risk Management (SCRM): an empirical investigation on French industrial firms", International Journal of Production Research, 52(11), pp. 3381-3403.

Lee, H. L., So, K. C. and Tang, C. S. (2000) "The value of information sharing in a two-level supply chain", Management science, 46(5), pp. 626-643.

Li, J., Sikora, R., Shaw, M. J. and Woo Tan, G. (2006) "A strategic analysis of inter organizational information sharing", Decision Support Systems, 42(1), pp. 251-266. 
Lin, F.-r., Huang, S.-h. and Lin, S.-c. (2002) "Effects of information sharing on supply chain performance in electronic commerce", IEEE Transactions on Engineering Management, 49(3), pp. 258-268.

Lindell, M. K. and Whitney, D. J. (2001) "Accounting for common method variance in crosssectional research designs", Journal of Applied Psychology, 86(1), pp. 114-121.

Liu, H., Ke, W., Wei, K. K., Gu, J. and Chen, H. (2010) "The Role of Institutional Pressures and Organizational Culture in the Firm's Intention to Adopt Internet-Enabled Supply Chain Management Systems", Journal of Operations Management, 28(5), pp. 372-384.

Liu, H., Ke, W., Wei, K. K. and Hua, Z. (2015) "Influence of power and trust on the intention to adopt electronic supply chain management in China", International Journal of Production Research, 53(1), pp. 70-87.

Lusch, R. F. and Brown, J. R. (1996) "Interdependency, Contracting, and Relational Behavior in Marketing Channels", The Journal of Marketing, 60(4), pp. 19-38.

Ming, Y., Grabot, B. and Houé, R. (2014) "A typology of the situations of cooperation in supply chains", Computers \& Industrial Engineering, 67, pp. 56-71.

Mitra, S. and Singhal, V. (2008) "Supply Chain Integration and Shareholder Value: Evidence from Consortium Based Industry Exchanges", Journal of Operations Management, 26(1), pp. 96-114.

Mizruchi, M. S. (1989) "Similarity of Political Behavior Among Large American Corporations", American Journal of Sociology, 95(2), pp. 401-424.

Moberg, C. R., Cutler, B. D., Gross, A. and Speh, T. W. (2002) "Identifying Antecedents of Information Exchange within Supply Chains", International Journal of Physical Distribution \& Logistics Management, 32(9), pp. 755-770.

Mohr, J. J. and Sohi, R. S. (1995) "Communication flows in distribution channels: Impact on assessments of communication quality and satisfaction", Journal of Retailing, 71(4), pp. 393415.

Mora-Monge, C. (2019) "Trust, power and supply chain integration in Web-enabled supply chains", Supply Chain Management: An International Journal, 24(4), pp. 524-539.

Murray, S. L., Holmes, J. G. and Griffin, D. W. (1996) "The Benefits of Positive Illusions: Idealization and the Construction of Satisfaction in Close Relationships", Journal of Personality and Social Psychology, 70(1), pp. 79-98.

Patnayakuni, R., Rai, A. and Seth, N. (2006) "Relational antecedents of information flow integration for supply chain coordination", Journal of Management Information Systems, 23(1), pp. 13-49.

Pfeffer, J. and Salancik, G. R. (1978) The external control of organizations: A resource dependence perspective. New York, NY: Harper \& Row. 
Preacher, K. J., Rucker, D. D. and Hayes, A. F. (2007) "Addressing moderated mediation hypotheses: Theory, methods, and prescriptions", Multivariate behavioral research, 42(1), pp. 185-227.

$\mathrm{Pu}, \mathrm{X}$. , Chan, F. T. S. and Chong, A. Y. L. "Development of a Unified Open E-Logistics Standards Diffusion Model For Manufacturing Supply Chain Integrations". The 20th Pacific Asia Conference on Information Systems (PACIS 2016), Chiayi, Taiwan, 27 June - 1 July, Paper 181.

Pu, X., Chan, F. T. S. and Chong, A. Y. L. "Factors Affecting the Adoption of Internet-enabled Supply Chain Management Systems: An Empirical Study in China". The 8th International Congress on Engineering and Information, Sapporo, Japan.

Pu, X., Chan, F. T. S., Tsiga, Z. and Niu, B. (2018b) "Adoption of internet-enabled supply chain management systems: Differences between buyer and supplier perspectives", Industrial Management \& Data Systems, 118(8), pp. 1695-1710.

$\mathrm{Pu}, \mathrm{X}$., Wang, Z. and Chan, F. T. S. (2018c) "Leveraging Open E-Logistic Standards to Achieve Ambidexterity in Supply Chain", Journal of Computer Information Systems, pp. 112.

Rai, A., Patnayakuni, R. and Seth, N. (2006) "Firm Performance Impacts of Digitally Enabled Supply Chain Integration Capabilities", MIS Quarterly, 30(2), pp. 225-246.

Rai, A. and Tang, X. (2010) "Leveraging IT Capabilities and Competitive Process Capabilities for the Management of Interorganizational Relationship Portfolios", Information Systems Research, 21(3), pp. 516-542.

Sahin, F. and Robinson, E. P. (2002) "Flow coordination and information sharing in supply chains: review, implications, and directions for future research", Decision sciences, 33(4), pp. 505-536.

Saldanha, J. P., Mello, J. E., Knemeyer, A. M. and Vijayaraghavan, T. A. S. (2015) "Implementing Supply Chain Technologies in Emerging Markets: An Institutional Theory Perspective", Journal of Supply Chain Management, 51(1), pp. 5-26.

Salvador, F., Chandrasekaran, A. and Sohail, T. (2014) "Product configuration, ambidexterity and firm performance in the context of industrial equipment manufacturing", Journal of Operations Management, 32(4), pp. 138-153.

Sezen, B. (2008) "Relative effects of design, integration and information sharing on supply chain performance", Supply Chain Management: An International Journal, 13(3), pp. 233 240 .

Shah, R., Goldstein, S. M. and Ward, P. T. (2002) "Aligning Supply Chain Management Characteristics and Interorganizational Information System Types: An Exploratory Study", IEEE Transactions on Engineering Management, 49(3), pp. 282-292.

Sheppard, B. H., Hartwick, J. and Warshaw, P. R. (1988) "The Theory of Reasoned Action: A Meta-Analysis of Past Research with Recommendations for Modifications and Future Research", Journal of Consumer Research, 15(3), pp. 325-343. 
Sila, I. (2015) "The state of empirical research on the adoption and diffusion of business-tobusiness e-commerce", International Journal of Electronic Business, 12(3), pp. 258-301.

Sodero, A. C., Rabinovich, E. and Sinha, R. K. (2013) "Drivers and outcomes of openstandard interorganizational information systems assimilation in high-technology supply chains", Journal of Operations Management, 31(6), pp. 330-344.

Tang, X. and Rai, A. (2012) "The Moderating Effects of Supplier Portfolio Characteristics on the Competitive Performance Impacts of Supplier-Facing Process Capabilities", Journal of Operations Management, 30(1), pp. 85-98.

Uzzi, B. (1997) "Social Structure and Competition in Interfirm Networks: The Paradox of Embeddedness", Administrative Science Quarterly, 42(1), pp. 35-67.

Vijayasarathy, L. R. (2010) "Supply integration: An investigation of its multi-dimensionality and relational antecedents", International Journal of Production Economics, 124(2), pp. 489505 .

Wooldridge, J. M. (2010) Econometric analysis of cross section and panel data. Cambridge, MA: The MIT press.

Wu, I.-L. and Chuang, C.-H. (2010) "Examining the diffusion of electronic supply chain management with external antecedents and firm performance: A multi-stage analysis", Decision Support Systems, 50(1), pp. 103-115.

Wu, W. p. (2008) "Dimensions of social capital and firm competitiveness improvement: The mediating role of information sharing", Journal of Management Studies, 45(1), pp. 122-146.

Yigitbasioglu, O. M. (2010) "Information sharing with key suppliers: a transaction cost theory perspective", International Journal of Physical Distribution \&amp; Logistics Management, 40(7), pp. 550-578.

Zhang, C. and Dhaliwal, J. (2009) "An investigation of resource-based and institutional theoretic factors in technology adoption for operations and supply chain management", International Journal of Production Economics, 120(1), pp. 252-269.

Zhao, K., Xia, M. and Shaw, M. J. (2007) "An Integrated Model of Consortium-Based EBusiness Standardization: Collaborative Development and Adoption with Network Externalities", Journal of Management Information Systems, 23(4), pp. 247-271.

Zhou, W., Chong, A. Y. L., Zhen, C. and Bao, H. (2018) "E-Supply Chain Integration Adoption: Examination of Buyer-Supplier Relationships", Journal of Computer Information Systems, 58(1), pp. 58-65.

Zhu, K., Kraemer, K. L., Gurbaxani, V. and Xu, S. X. (2006) "Migration to Open-Standard Interorganizational Systems: Network Effects, Switching Costs, and Path Dependency", Mis Quarterly, 30(Special Issue on Standard Making), pp. 515-539. 